DOI: $10.32481 / \mathrm{djph} .2021 .07 .005$

\title{
Poverty, Racism, and Its Impact on Riverside
}

\author{
Logan Herring
}

CEO, The WRK Group

Let's be honest with ourselves for a moment. Poverty and racism are two sides of a centuries old coin. In fact, “...the correlation between poverty and race is undeniable; both statistics and life experiences confirm the connection. Communities of color, especially Black and Hispanic communities, experience much higher rates of income shortfalls than the population categorized as White non-Hispanic."1 This isn't new information, in fact, it's far from it. But it is relevant.

The Riverside Neighborhood, located in Wilmington, Delaware, is a real example of the impact of systemic racism and poverty in a local community. The Riverside Neighborhood was originally built to create an affordable neighborhood for White veterans returning from World War II. The GI bill, which gave many returning veterans the opportunity to obtain a mortgage, home, and in time, the development of generational wealth, didn't necessarily extend to returning Black veterans.

Though the bill helped White Americans prosper and accumulate wealth in the postwar years, it didn't deliver on that promise for veterans of color. In fact, the wide disparity in the bill's implementation ended up helping drive growing gaps in wealth, education, and civil rights between White and Black Americans. ${ }^{2}$

As a result, White veterans, their families, and their newly attained mortgages, were able to leave the Riverside Neighborhood as they pursued the "American Dream" and a life in the suburbs. Today, this mass exodus is known as "White Flight," and the ripple effects remain present even today.

As subsidized housing became available, low-to-no-income Black Americans began to move into Riverside. Without the benefit of home ownership, a major contributor to generational wealth and stability, it became harder and harder for Riverside residents to flourish and grow.

Decades later, the effects of the flawed GI Bill and other contributing factors to systemic racism - such as mass incarceration - are widely felt by today's residents. In fact, today's Riverside is a challenging landscape that includes unsettling statistics about the neighborhood and its potential future:

- 70 percent of children in Riverside live below the poverty line compared to 25 percent of children in Delaware,

- 68 percent unemployment rate in public housing,

- 41 percent of adults are without a high school diploma,

- Median household income is \$9,277 in subsidized housing (\$23,456 in nonsubsidized housing),

- 87 percent of households are led by single women 
DOI: $10.32481 / \mathrm{djph} .2021 .07 .005$

\section{The Digital Divide}

One of the ripple effects of systemic racism and poverty that regularly effects the Riverside Neighborhood is the lack of access to high-speed internet. Commonly referred to as the digital divide, this separation from a tool that has become a basic necessity has long-reaching effects. Research has shown that "low-income households and people of color are less likely to have home-internet connections. But if they do connect at home, they are more likely to rely solely on mobile wireless." ${ }^{3}$

While a mobile wireless connection offers some assistance, "mobile-only households do not have access to the full benefits of fixed broadband connections. Fixed connections typically offer far greater speeds and higher data caps (or no caps). Furthermore, a mobile connection may not always be available to everyone in the household if the primary account holder takes the only mobile device with them when they leave the home." ${ }^{3}$

Also, at its root, internet is an incredibly expensive commodity. Mobile access offers more diverse payment options and can eliminate the barrier of credit checks that home internet requires.

A major reason for this difference between wired and mobile is that the mobile market is more competitive (for now), with incumbent providers and resellers offering lower-cost plans with no credit checks, and specifically marketing them to low-income families and people of color.... But no such plans exist for wired-broadband options with higher capacity and faster speeds than wireless, like cable or fiber. If you want wired home internet, you have to pass a credit check and credit checks have long fueled racial discrimination. ${ }^{4}$

Imagine having to conduct a job search, research a school project, or write a resume with only your mobile device for assistance. To bring it even more closely to home, there is no way I could have done my research or event typed up this article without the support of a laptop and highspeed internet at my fingertips.

\section{The WRK Group}

Now, before you start to worry that this is yet another article that leaves you with feelings of insurmountable obstacles and no clear path forward, let me relieve your fears. This is an article that lets you know that, even though there are challenges, BIG CHALLENGES, on the path to rectify what years of slavery, Jim Crow laws, segregation, and ongoing racism have embedded in our American culture, there are still ways to move forward.

The WRK Group, comprised of The Warehouse, REACH Riverside, and Kingswood Community Center, is a collaboration of three organizations focused on developing and enhancing the health and well-being of the Riverside Neighborhood.

- The Warehouse

- Developed "For Teens, By Teens"

- Innovative, one-stop center serving ages 13 to 19

- Teen-driven programming focused on recreation, education, arts, career, and health

- Collaborating with over 140 youth-serving organizations 
DOI: $10.32481 /$ djph.2021.07.005

- Three goals: safety, educational support, and workforce readiness

- $\underline{\text { REACH Riverside }}$

- Developed "With the Community, For the Community"

- Member of the national Purpose Built Communities

- \$250 million holistic revitalization effort

- Redevelopment: Up to 600 units of high quality, mixed-income housing

- Education: cradle-to-college and career readiness pipeline

- Community Health: health, wellness, safety services, and programming

- Kingswood Community Center

- Empowering the Community of Riverside and Northeast Wilmington since 1946

- Early Learning Academy: high quality, evidence-based programming (ages one through five)

- School-age services (ages six through twelve): before, after-school, and summer programming

- Jimmy Jenkins Senior Center: activities to remain healthy and self-sufficient

- Kingswood Academy: alternative school, located at The Warehouse (seventh through twelfth grade)

- Preparing for the development of a new, state-of-the-art facility that will replace and enhance the current community center

With the goal of empowering the community to reach its full potential by eliminating the barriers of structural racism and revolutionizing teen engagement, The WRK Group has seen the direct impact of poverty, systemic racism, and the digital divide, and we are meeting the challenge head-on.

- Riverside Relief Fund: When COVID-19 hit our communities in 2020 and schools began to transition from brick-and-mortar education to virtual classrooms, The WRK Group quickly realized that Riverside was not set up for success. That's why they began the Riverside Relief Fund. In a short period of time, The WRK Group was able to distribute over 400 Chromebooks to Riverside families. In some scenarios, this was the first device with internet access for a household, allowing students to participate in virtual studies and providing adults with the tools they need to be successful.

- Comcast Lift Zone: Kingswood Community Center partnered with Comcast to create a "Lift Zone." About one-fourth of households in Wilmington have no internet access, according to 2018 Census Bureau estimates. ${ }^{5}$ In September 2020, Comcast announced a multiyear program to launch more than 1,000 Wi-Ficonnected Lift Zones in community centers nationwide. This effort is part of its ongoing commitment to help connect low-income families to the Internet and 
provide resources to help them fully participate in educational opportunities and the digital economy. The newly established Lift Zone now provides high speed internet to the local community at no cost to the individual.

- ChristianaCare Virtual Health: The WRK Group and its partner, ChristianaCare, have recently established the first primary health care provider in the community. Appointments are made via mobile phone with virtual and in-person availability. Locals are now able to obtain physicals for school or sports teams as well as having access to additional care and consultation when sick.

\section{What Can I Do?}

Through these endeavors and initiatives, The WRK Group continues to look for opportunities to diminish the barriers that many people of color experience daily. They know that simply closing the digital divide will not end systemic racism or poverty, but it is one of many tools they can use to bring justice to an underserved and undervalued neighborhood. So, how can you help?

- Donate Today: Non-profits like The WRK Group need your support to eliminate barriers to success. Whether giving monthly or providing a one-time gift, your donation is incredibly valued.

- Learn More: Visit www.wrkgroup.org to learn more about the Riverside neighborhood and other ways you can get involved.

- Talk to Them: The best way to learn about The WRK Group is to have a good oldfashioned chat! Email today to sign up for a lunch and learn where you can learn more about this incredible neighborhood and where it is headed.

\section{References}

1. Anti-Poverty Network of New Jersey. (2017, September). Anti-Poverty Network. The Uncomfortable Truth. Retrieved from:

http://www.antipovertynetwork.org/resources/Documents/The\%20Uncomfortable\%20Truth $\% 20$ Final $\% 20-\% 20$ web.pdf

2. Blakemore, E. (2019, June 21). How the GI Bill's Promise Was Denied to a Million Black WWII Veterans. History.com. https://www.history.com/news/gi-bill-black-wwii-veteransbenefits

3. Turner, D. (2016, December). Digital Denied: The Impact of Systemic Racial Discrimination on Home-Internet Adoption. Free Press. https://www.freepress.net/sites/default/files/legacypolicy/digital_denied_free_press_report_december_2016.pdf

4. Floberg, D. (2018, December 13). The Racial Digital Divide Persists. Free Press. https://www.freepress.net/our-response/expert-analysis/insights-opinions/racial-digitaldivide-persists

5. Neiburg, J. (2021, April 17). Comcast's 'Lift Zones' in Wilmington, Newark aim to help lowincome families get online. The News Journal.

https://www.delawareonline.com/story/news/2021/04/17/comcasts-lift-zones-help-lowincome-families-get-online-delaware-internet-access-virtual-learning/7259961002/ 
DOI: $10.32481 /$ djph.2021.07.005

Copyright (c) 2021 Delaware Academy of Medicine / Delaware Public Health Association.

This is an Open Access article distributed under the terms of the Creative Commons Attribution Non-Commercial License (https://creativecommons.org/licenses/by-nc-nd/4.0/) which permits unrestricted non-commercial use, distribution, and reproduction in any medium, provided the original work is properly cited. 